\title{
Simulation of the ENSO influence on the extra-tropical middle atmosphere
}

\author{
Tatiana S. Ermakova* ${ }^{*}$, Olga G. Aniskina, Irina A. Statnaia, Maxim A. Motsakov and Alexander I. Pogoreltsev
}

\begin{abstract}
The impact of the El Niño Southern Oscillation (ENSO) on the Northern Hemisphere mid-winter zonal wind, temperature, and stationary planetary waves (SPWs) is evaluated using the Middle and Upper Atmosphere Model and Modern-Era Retrospective Analysis for Research and Applications (MERRA). The composites determined using simulated ensembles and MERRA winters with different ENSO phases show that the mean zonal wind in the stratosphere at higher-middle latitudes is weaker and polar region is warmer, and the activity of SPW1 is higher during El Niño events. The simulated and observed SPW2 amplitude behaves in the opposite way, and it is stronger in the stratosphere during La Niña. The observed changes of SPW1 and SPW2 amplitudes under La Niña and El Niño events should affect an efficiency of the stratosphere-troposphere coupling in different longitudinal sectors through the changes in horizontal distributions of the downward wave activity flux.
\end{abstract}

Keywords: El Niño Southern Oscillation (ENSO), Stationary planetary waves (SPWs), Sudden stratospheric warming (SSW), Middle and Upper Atmosphere Model (MUAM)

\section{Introduction}

Tropical deep convection is responsible for intensive rainfall and subsequent latent heat release in the low latitude troposphere. Spatial and temporal variations of the latent heat release excite planetary-scale waves and thermal tides, which, upon propagation and dissipation, affect the global circulation at higher altitudes. Another prominent atmospheric phenomenon in the tropical troposphere is the El Niño Southern Oscillation (ENSO) (Philander 1990). The ENSO is well recognized as a significant predictor of climate anomalies (Coelho and Goddard 2009; Larkin and Harrison 2005; Wu et al. 2003) whose global impact is seen not only in the tropics but in extra-tropics as well through teleconnections (Gershunov and Barnett 1998; Horel and Wallace 1981; Jin et al. 2016). The stratospheric processes are naturally involved in these teleconnections. In particular, considerable ENSO signatures have been discovered in the northern extra-tropical stratosphere in the observational data (Van

\footnotetext{
*Correspondence: taalika@mail.ru

Department of Meteorological Forecasts, Russian State

Hydrometeorological University, Voronezhskaya 79, St. Petersburg, Russia
} 192007
Loon et al. 1982; Labitzke and Van Loon 1989; Camp and Tung 2007; Free and Seidel 2009; Butler and Polvani 2011; Xie et al. 2014a, b; Rao and Ren 2016a) and reproduced in simulations (Sassi et al. 2004; Garcia-Herrera et al. 2006; Manzini et al. 2006; Brönnimann et al. 2006; Rao and Ren 2016b). However, the changes in forcing of stationary planetary waves (SPWs) by the latent heat release dependent on the ENSO phase and contribution of this heating to the zonally averaged thermal budget of troposphere have not been considered explicitly in these studies. SPWs generated in the troposphere propagate upward into the stratosphere, where they dissipate or are nonlinearly saturated (Giannitsis and Lindzen 2009) and, thus, affect the stratospheric circulation by depositing their momentum and energy to the mean flow. If the phase velocity of a wave harmonics approaches the zonal mean wind, the direction of wave propagation changes due to refraction (Matsuno 1970) or reflection (Perlwitz and Harnik 2003; Harnik 2009; Nath et al. 2016). The reflected waves act against the incident harmonics, which can result in changes in the zonal mean flow in the troposphere (Lin 1982). In the latter study it was shown that weak westerly winds favor vertical propagation of SPWs. To the key parameters controlling the wave 
vertical propagation should be added the vertical shear of buoyancy frequency (Chen and Robinson 1992). Finally, vertical shears of the mean zonal wind can impede (Limpasuvan and Hartmann 2000) or enhance (Hu and Tung 2002) planetary wave propagation.

Global distributions of precipitation rates under La Niña and El Niño conditions differ substantially (Salby 2012). Latent heat release can influence SPWs at stratospheric heights in two ways: explicitly through their additional thermal forcing in the troposphere and implicitly via altering the mean zonal flow, whose distribution determines the propagation conditions of SPWs (Jacqmin and Lindzen 1985). The main purpose of the present investigation is to develop a new parameterization of atmospheric heating rates caused by latent heat release that takes into account the diurnal and longitudinal variations as well as its dependence on the ENSO phase. This parameterization has been implemented into the Middle and Upper Atmosphere Model (MUAM) (Pogoreltsev et al. 2007), and a set of ensemble simulations corresponding to the El Niño and La Niña conditions accounting for the differences in the lower boundary forcing of SPWs has been performed.

\section{Heating rates and lower boundary conditions}

To estimate the latent convection heating due to condensation, the Modern-Era Retrospective Analysis for Research and Applications (MERRA) convective precipitation data have been used (Rienecker et al. 2011). The distribution of heating rates is calculated using the empirical formula suggested by Hong and Wang (1980). This formula was obtained on the basis of the measurements (Reed and Recker 1971):

$$
J(z, \lambda, \phi)=J_{Z}(z) J_{\lambda \phi}(\lambda, \phi),
$$

where $J_{\lambda \phi}(\lambda, \phi)$ is the observed longitude/latitude distribution of precipitation rates near the ground and $J_{Z}(z)$ is the empirical formula for the vertical distribution of the latent heating rates depending on the precipitation rate near the ground:

$$
J_{Z}(z)=A\left\{\exp \left[-\left(\frac{z-6.5}{5.39}\right)^{2}\right]-0.23 \exp \left(-\frac{z}{1.31}\right)\right\} .
$$

In formula (2), $A$ is the empirical constant, which depends on the precipitation rate. $(A=8.54 \mathrm{~mW} / \mathrm{kg}$ corresponds to the rainfall rate of $1.6 \mathrm{~mm} /$ day.) Equations (1) and (2) have been successfully used to calculate the thermal forcing of nonmigrating tides (Forbes et al. 1997; Hagan and Forbe 2002). The heating rate has been calculated using the same constant $A$ and MERRA precipitation data for selected El-Nino and La-Nina years, which then has been implanted in a new parameterization as the zonally averaged values, SPWs, and tidal components.

There are many different indices available that seek to describe ENSO events, e.g., NINO 3, NINO 3.4, Oceanic Niño Index (ONI), the Southern Oscillation Index (SOI), the Multivariate ENSO Index (MEI). In the present study, MEI has been used. It is based on the set of six main observables over the tropical Pacific variables. These six variables are sea-level pressure, zonal and meridional components of the surface wind, sea surface temperature, surface air temperature, and total cloudiness fraction of the sky (https://www.esrl.noaa.gov/psd/enso/mei/). Using the table of available MEI values (http://www.esrl. noaa.gov/psd/enso/mei/table.html) the following sets of Januaries of 1983, 1992, 1998, 2003, 2010 and of 1989, 1999, 2000, 2008, 2011 have been chosen, which are representative of El Niño and La Niña conditions, correspondingly. The composites for the latent heat release and lower boundary conditions for January of these years have been prepared using the MERRA and Japanese 55-year Reanalysis (JRA-55) (Kobayashi et al. 2015) data, respectively.

The longitude/latitude distributions of thus-calculated monthly averaged latent heating composites for Januaries under the El Niño and La Niña conditions at the altitude of $7 \mathrm{~km}$ are shown in Fig. 1. Figure 1c presents the difference between heating rates for the El Niño and La Niña cases. It demonstrates a difference of up to $1.5 \mathrm{~K} \mathrm{day}^{-1}$ in low latitudes that can provide us with additional thermal forcing of SPWs in the troposphere.

The latent heating rates have been calculated at all latitudes, longitudes, and altitudes at the MUAM grid points using Eq. (2) and 3-hourly MERRA precipitation rate data taking into account the diurnal variations. The longitudinal distribution of the heating rates was approximated by a set of zonal harmonics with zonal wave numbers $m=1-4$. In order to take account of local (or universal) time changes in the MUAM, each zonal harmonic is presented by the stationary wave and time harmonics with periods $T=24$ and $12 \mathrm{~h}$ with the separation into the waves traveling to the west and to the east. Thus, the heating rates can be calculated at any model time resolving the mean zonal values, longitudinal variations (i.e., SPWs), and a set of diurnal and semidiurnal tidal oscillations. In Fig. 2 the latitude/altitude distributions of the composite (5-years averaged) heating rates caused by latent heat release obtained for El Niño and La Niña Januaries are presented. The top panels of this figure, which show the zonally mean values of the latent heating rates, demonstrate maxima in the equatorial area of the Southern Hemisphere. Under the La Niña conditions the maximum of heating is broader spatially and spreads into the Northern Hemisphere. The additional heating in 
(a) LH release (K/day), El-Nino, $7 \mathrm{~km}$

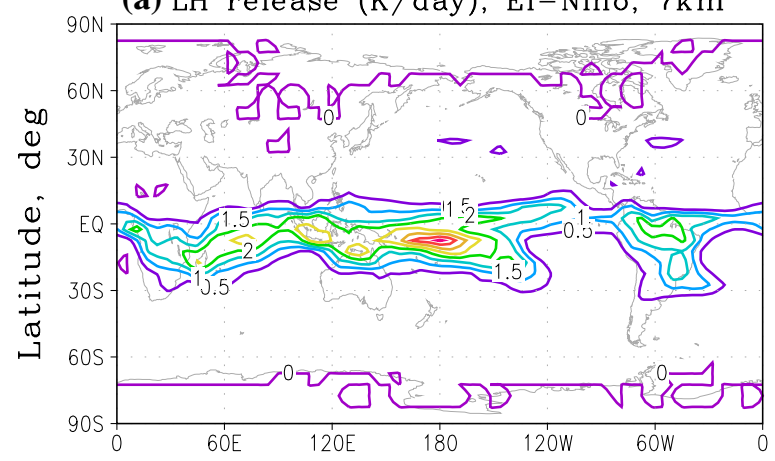

(b) LH release (K/day), La-Nina, $7 \mathrm{~km}$

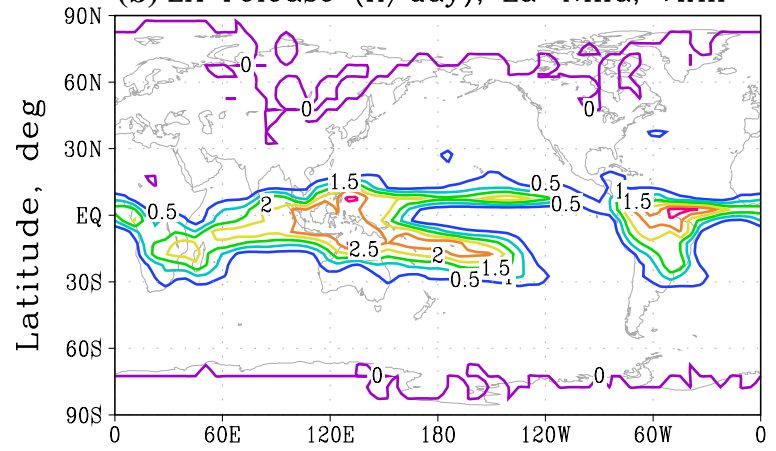

(c) Difference EN - LN (K/day), $7 \mathrm{~km}$

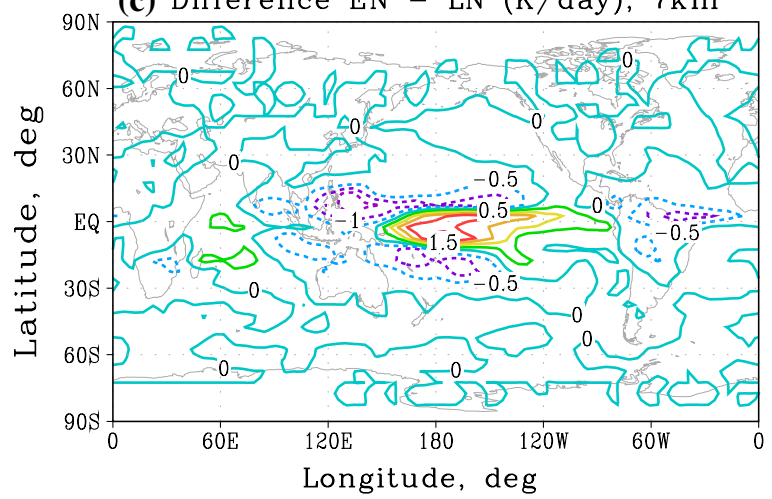

Fig. 1 Monthly mean (January) latent heat distribution at $7 \mathrm{~km}$ altitude during El Niño (a) and La Niña (b) conditions; heating difference of El Niño and La Niña (c)

the equatorial area leads to an increase in the latitudinal temperature gradient at the middle latitudes that causes an amplification of the jet streams in the troposphere. This strengthening, in turn, affects the efficiency of SPW propagation into the stratosphere. Within several days, interactions of the waves and the mean flow taking place during the intensification of SPWs result in the polar vortex weakening that can initiate sudden stratospheric warmings (SSWs). Thus, it is necessary to analyze the contribution of latent heating to the forcing of these waves. In Fig. 2, the results of Fourier decomposition of heating due to latent heat release obtained using MERRA precipitation rate data are presented. These heating rates are used as input in simulation experiments with the MUAM. The middle and lower panels of Fig. 2 show the amplitudes of the thermal forcing for SPWs with the zonal wave numbers $m=1$ and 2 under El Niño and La Niña conditions (panels $c, e$ and $d, f$, respectively). The forcing of the harmonic with zonal wave number $m=2$ (hereafter, SPW2) at lower latitudes in Fig. $2 f$ (La Niña conditions) is considerably stronger than that for the El Niño conditions (Fig. 2e). Stronger heating above South America under La Niña (Fig. 1b) leads to a substantial increase in the SPW2 forcing. There exist also some changes in the SPW1 thermal forcing at the low latitudes in the Northern Hemisphere. The amplitudes of SPW3 and SPW4 in latent heating do not demonstrate noticeable differences between the La Niña and El Niño conditions and, therefore, are not shown here.

The longitude/latitude distributions of monthly mean (January) composites of the geopotential height and temperature under El Niño and La Niña conditions calculated from JRA-55 data at the $1000 \mathrm{hPa}$ pressure level (the lower boundary of the MUAM) are shown in Fig. 3. The bottom panels present the differences in the geopotential height and temperature between the El Niño and La Niña composites. Evidently, there are no large-scale longitudinal variations and the differences in the lower boundary forcing of the SPW1 and SPW2 are not significant.

Multiple simulations with the MUAM have been performed to investigate the ENSO signal in the middle atmosphere. The latest version of MUAM includes new parameterizations: effects of orographic gravity waves (Gavrilov and Koval 2013; Gavrilov et al. 2015) and normal atmospheric modes (Pogoreltsev et al. 2014). The updated version of MUAM uses the climatological 3D distributions of ozone (Suvorova and Pogoreltsev 2011) and water vapor in the troposphere taking into account longitudinal variations (Ermakova et al. 2017). The scheme of numerical experiments is the same as described in Pogoreltsev et al. (2007): A fixed zenith angle of the Sun related to the 1st of January was used till 330 model days, and then, its seasonal changes have been included. Thus, 330-400 model days correspond to January-February and early March conditions. Two ensembles of 10 members for the El Niño and La Niña conditions have been obtained. The method of setting up different ensemble members was the same as described in Pogoreltsev et al. (2007).

\section{Effects of the ENSO in the Northern Hemisphere extra-tropics}

The results of simulation and MERRA data had been decomposed into Fourier series including the zonally averaged value and four largest zonal harmonics. These harmonics were separated into the sum of steady value and a set of westward and eastward propagating diurnal 
(a) Zonally averaged heating, K/day, EN

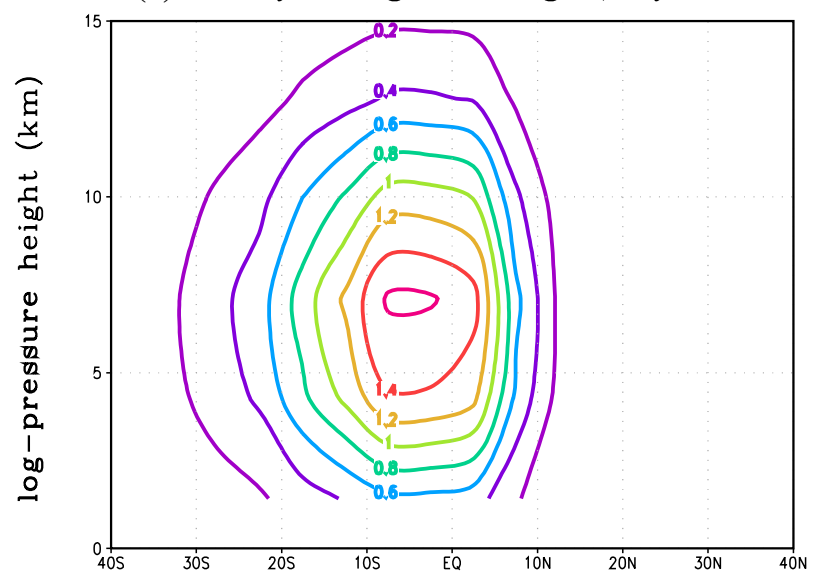

(c) SPW 1 forcing, K/day, El-Nino

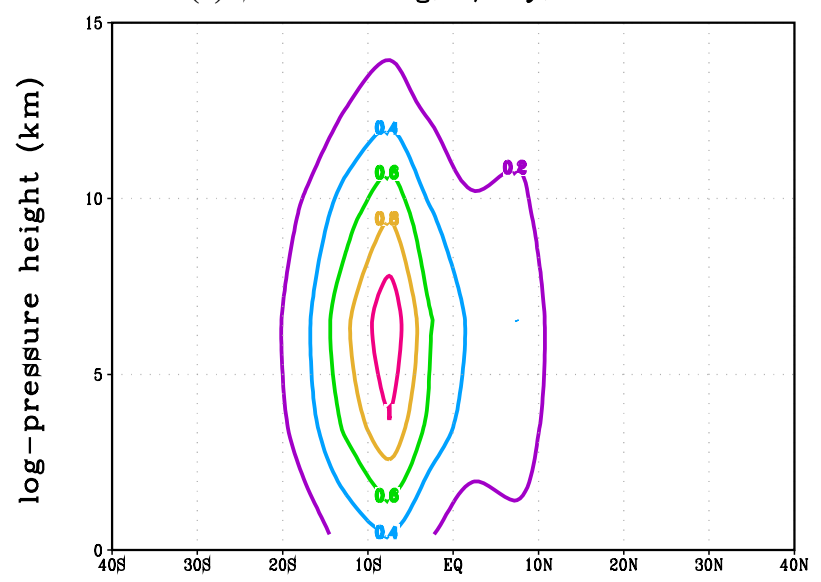

(e) SPW2 forcing, K/day, El-Nino

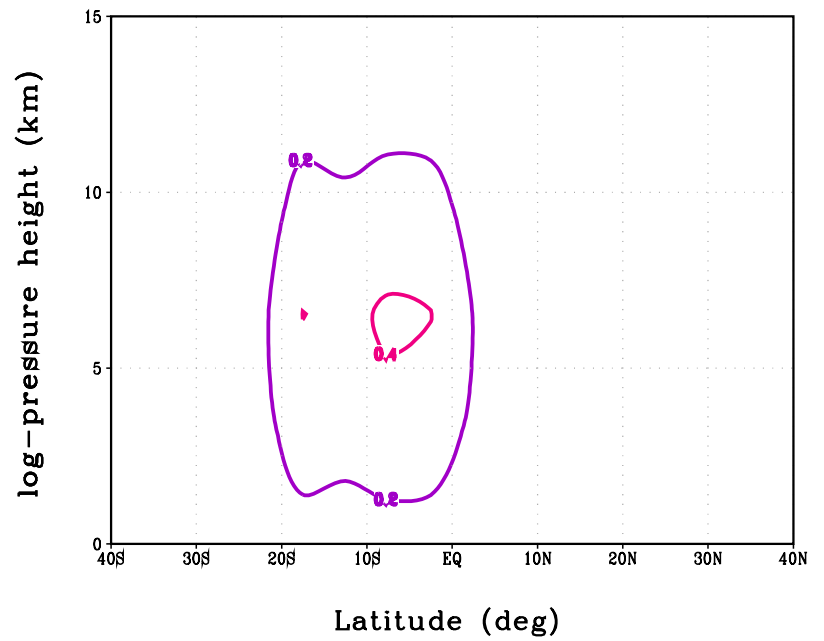

(b) Zonally averaged heating, K/day, LN

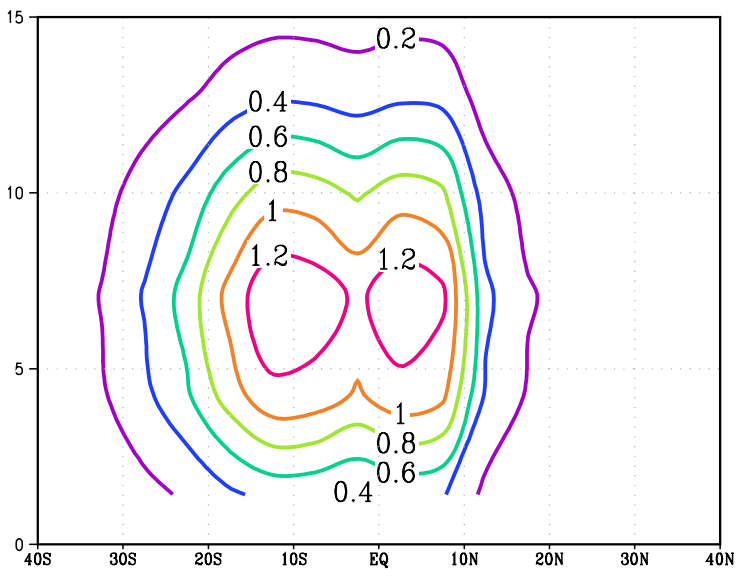

(d) SPW 1 forcing, K/day, La-Nina

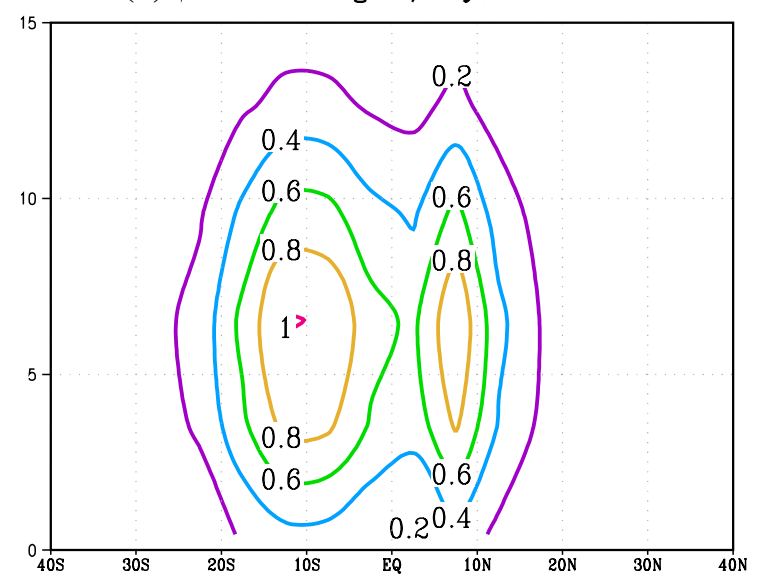

(f) \$PW2 forcing, K/day, La-Nina

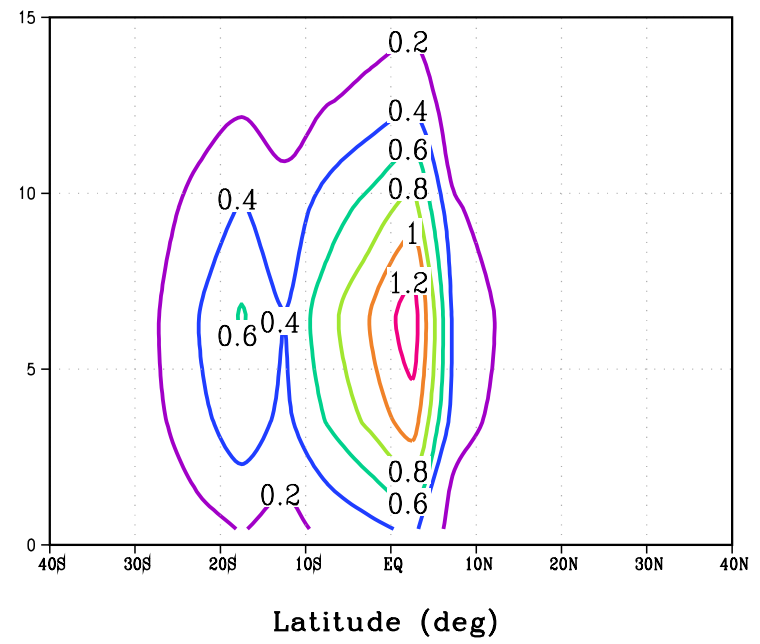

Fig. 2 Zonally averaged heating $(\mathbf{a}, \mathbf{b})$; thermal forcing of the SPW1 (c, d) and SPW2 (e, f). Left panels correspond to the El Niño and right panels to the La Niña conditions 


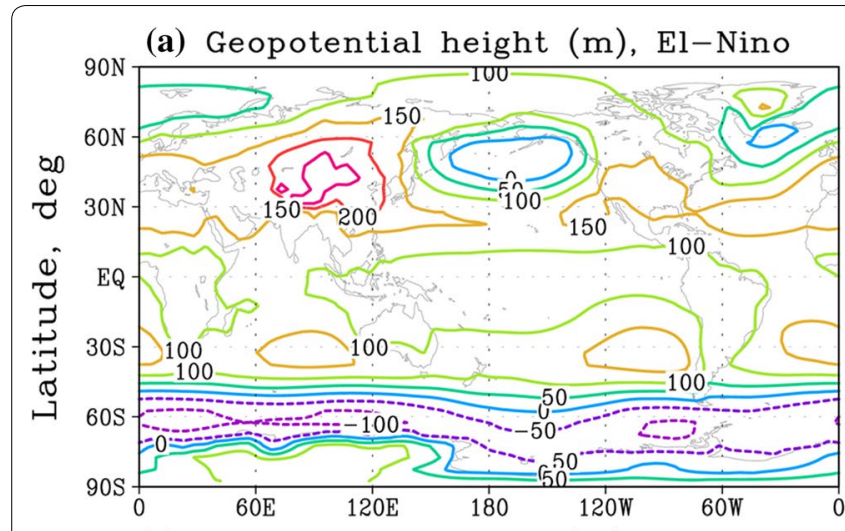

(c) Geopotential height (m), La-Nina
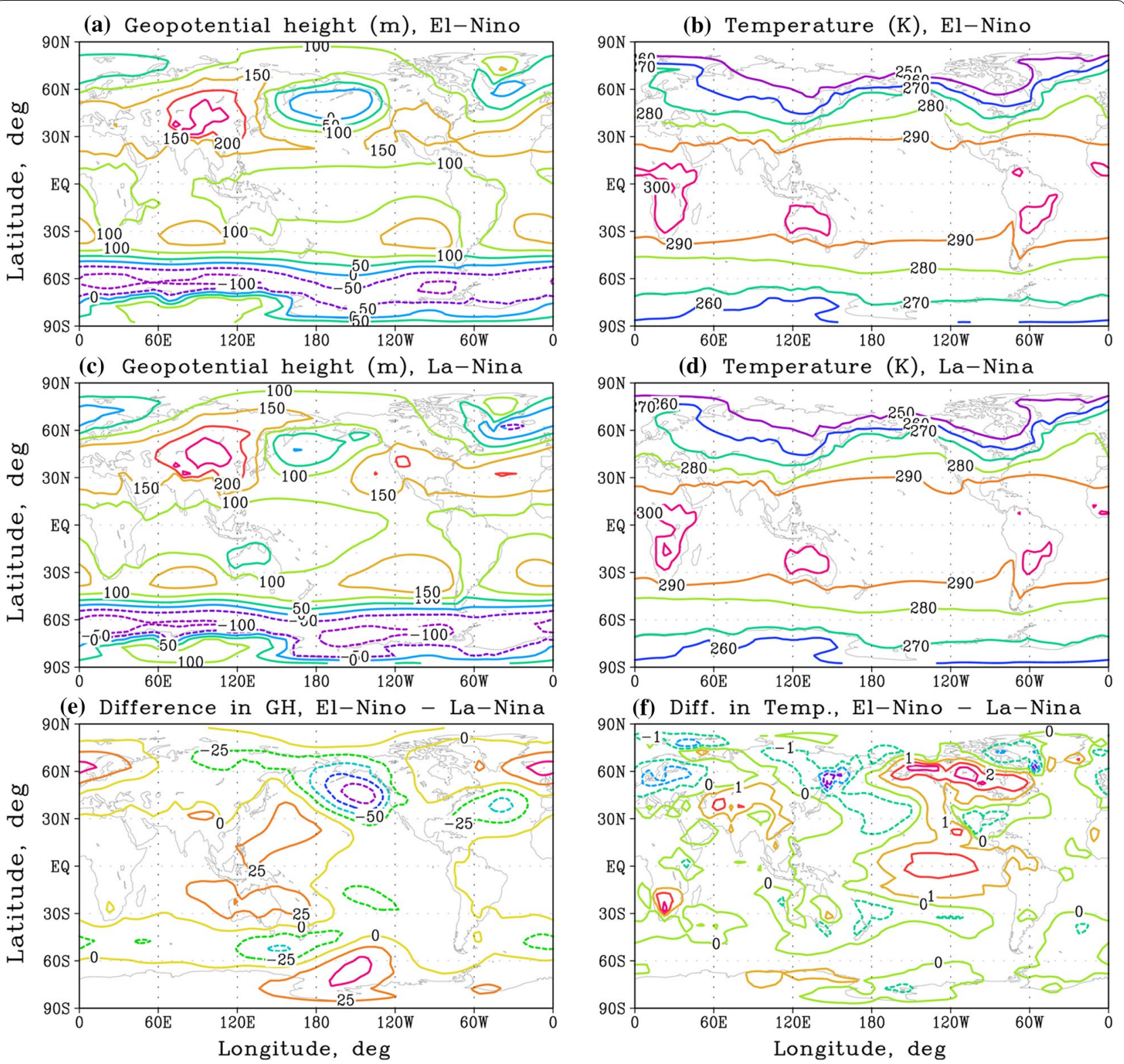

Fig. 3 Monthly mean (January) lower boundary conditions in the geopotential height $(\mathbf{a}, \mathbf{c})$ and temperature $(\mathbf{b}, \mathbf{d})$. Top panels correspond to the El Niño and middle panels to the La Niña conditions. Differences in the lower boundary conditions $(\mathbf{e}, \mathbf{f})$

and semidiurnal tidal components using the least squares fitting. The investigation of atmospheric tides is out of the scope of the present paper, and the only zonally averaged fields and large-scale longitudinal disturbances (SPWs) are considered. The results obtained are presented in Fig. 4. To ensure a better statistics, all composites have been calculated for the fields averaged over the middle winter months (January-February). Contours in the left panels of this figure show the composites of the zonal mean wind, temperature (Fig. 4a, d), SPW1, and SPW2 amplitudes in the geopotential height (Fig. 4g, j) simulated with the MUAM under the La Niña conditions. The shaded areas in these panels denote standard deviations that have been determined during the ensemble averaging over 10 members. The panels in the middle column of Fig. 4 show the composite differences in zonal mean wind, temperature (Fig. 4b, e), SPW1, and SPW2 amplitudes (Fig. 4h, k) between the El Niño and La Niña cases obtained with the MUAM. The right panels of Fig. 4 present the results obtained using MERRA data for the selected years. The shaded areas in the middle and right panels represent the statistical significance 
(a) Zonal wind, LN, MUAM

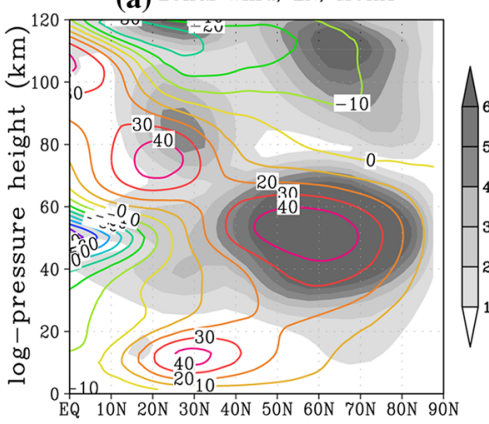

(d) Temperature, LN, MUAM

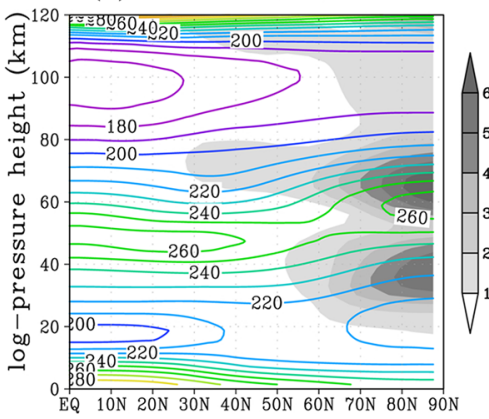

(g) SPW1 in geop. height, LN, MUAM

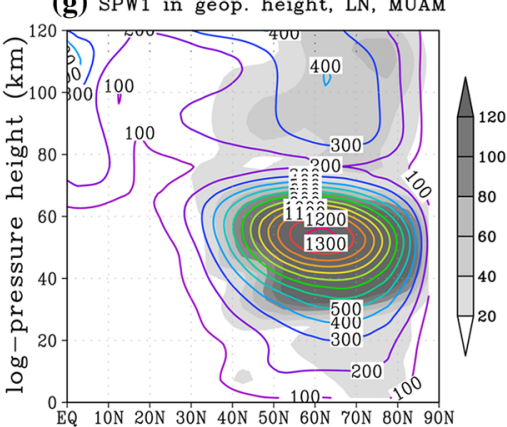

(j) SPW2 in geop. height, LN, MUAM

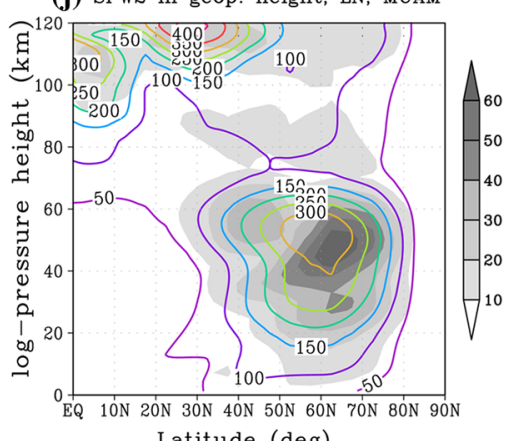

(b) Diff. EN-LN zonal wind, MUAM

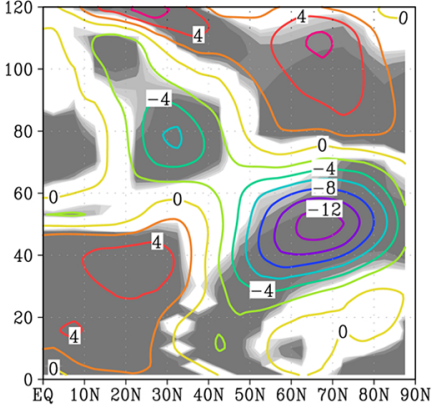

(e) Diff. EN-LN temperature, MUAM

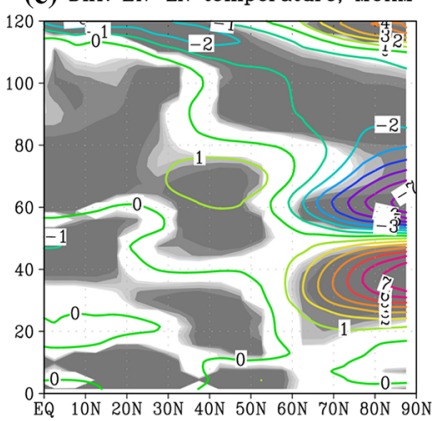

(h) EN-LN SPW1 geop. height, MUAM

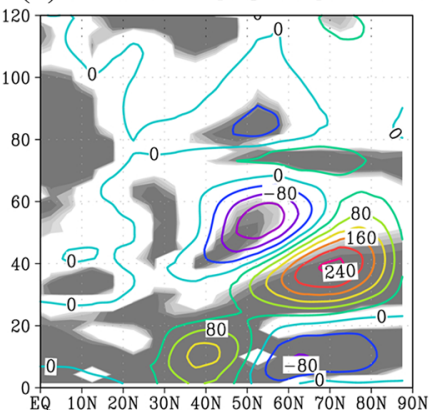

(k) EN-LN SPW2 geop. height, MUAM

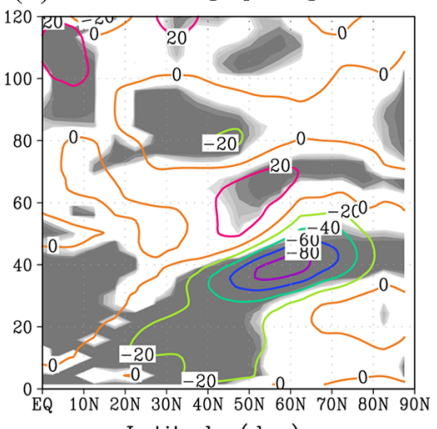

(c) Diff. EN-LN zonal wind, MERRA

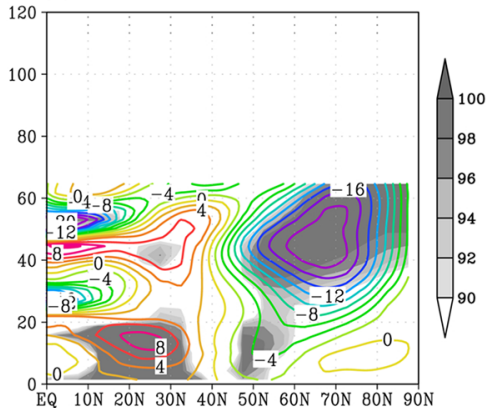

(f) Diff. EN-LN temperature, MERRA

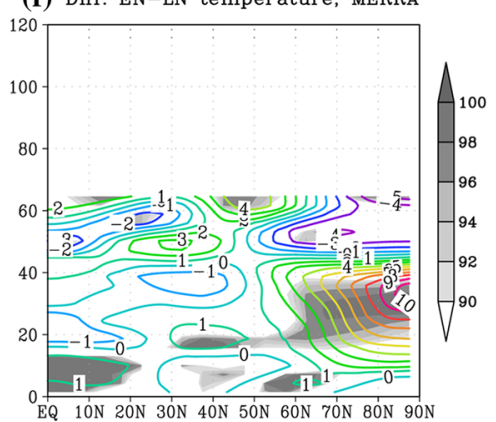

(i) EN-LN SPW1 geop. height, MERRA

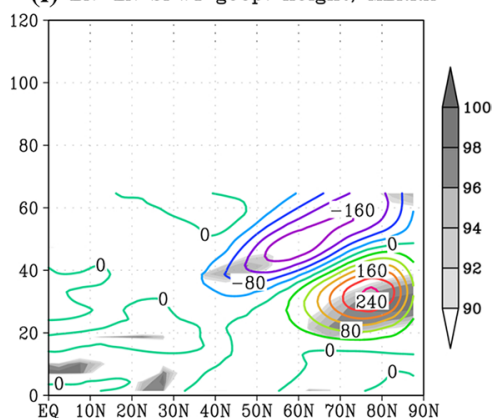

(l) EN-LN SPW2 geop. height, MERRA

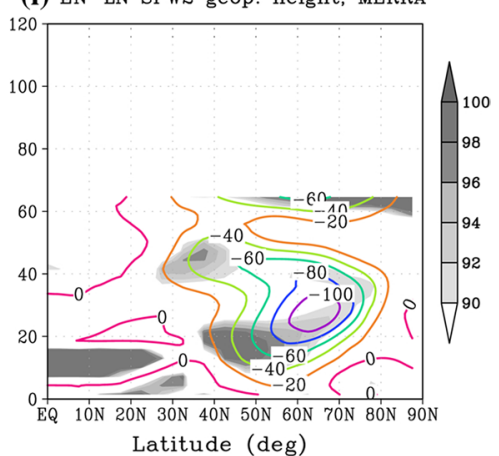

Fig. 4 Composites of the mean zonal wind (a), temperature (d), amplitudes of SPW1 (g) and SPW2 (j) in the geopotential height simulated with the MUAM under La Niña conditions (color contours). The corresponding differences (b, e, h, k) between ensembles with El Niño and La Niña (color contours). The right panels show the same differences but calculated using the MERRA data (c, $\mathbf{f}$, I, I). The shaded areas in the left panels indicate the standard deviations obtained during the ensemble averaging. The shaded regions in the middle and right panels denote the statistical significance 
of the differences. The comparison of the simulation results demonstrates that stratospheric polar vortex tends to be weaker and the polar region in lower stratosphere is warmer during El Niño events. The composites of the SPW1 amplitude are smaller at higher-middle latitudes in the lower stratosphere and stronger in the upper stratosphere under the La Niña conditions. The SPW2 behaves in the opposite way and has larger amplitudes at the stratospheric levels. The results of simulations are in a good agreement with the observed differences for the zonal mean wind, temperature, and amplitudes of SPWs, as is revealed from the MERRA reanalysis data. These differences are obviously related to the changes in the forcing and propagation of SPWs associated with the ENSO-induced changes in the distributions of latent heating. The SPWs propagation conditions are very sensitive to the changes of the mean zonal flow distribution in the troposphere (Jacqmin and Lindzen 1985). The latent heat release provides us with an additional zonally averaged heating and thermal forcing of SPWs at the low latitudes, which are different under El Niño and La Niña conditions. Both factors are responsible for the observed changes in SPW amplitudes. An additional zonally averaged heating at low latitudes in the Northern Hemisphere leads to changes in the intensity and position of the tropospheric jet, and the waveguide for SPW1 becomes wider in the case of El Niño. This can explain the obtained differences of the SPW1 amplitude in the stratosphere. The similar result was obtained when the climatic variability of SPW1 amplitude observed during the last decades was investigated (Kanukhina et al. 2008). The difference in the SPW2 amplitude at stratospheric heights can be accounted for by a substantial rise in the thermal forcing of this wave under La Niña conditions presented in Fig. 2f. A substantial increase in SPW1 amplitude under El Niño conditions leads to additional heating of the polar region and decrease in zonal mean flow due to nonlinear wave mean flow interaction.

\section{Summary and discussion}

Model experiments and the MERRA data have been used to analyze the extra-tropical ENSO signals in the Northern Hemisphere boreal middle atmosphere. The results of simulations with the MUAM and reanalysis data demonstrate similar ENSO manifestations in the fields of the mean zonal wind, temperature, and SPW1 and SPW2 amplitudes. Stratospheric polar vortex becomes substantially weaker, and the polar region is warmer during El Niño events. At the altitudes of the upper stratosphere and mesosphere, the temperature effect has the opposite sign. The composites obtained with the MUAM simulations show that the mean zonal wind in the lower thermosphere at higher-middle latitudes is stronger during El Niño. This, however, cannot be deduced from the MERRA data. The activity of SPW1 is higher in the stratosphere and weaker at middle latitudes in the region of the stratospheric jet maximum during El Niño's mid-winter. The simulated and observed SPW2 amplitude behaves in the opposite way and is larger in the stratosphere during La Niña. The obtained changes in SPW1 and SPW2 amplitudes under La Niña and El Niño events should affect the efficiency of the stratosphere-troposphere coupling, and the influence of stratospheric processes on circulation patterns in the troposphere can be manifested in different longitudinal sectors.

In recent studies, the question concerning the difference in the frequency of SSW events under El Niño and La Niña conditions has been discussed (Taguchi and Hartmann 2006; Butler and Polvani 2011; Garfinkel et al. 2012). The analysis of the MERRA data performed for years with different ENSO phases and the results of simulations with the MUAM show that the development of SSWs during the El Niño and La Niña events proceeds somewhat differently. The main heating of the polar region during La Niña is situated in the upper stratosphere (the altitude of about $40 \mathrm{~km}$ ), and the major SSWs could not be identified in this case basing on the analysis of the temperature and mean zonal wind behavior at $10 \mathrm{hPa}$ level (Pogoreltsev et al. 2015; Savenkova et al. 2017). In particular, the SSWs in January and February 2008 under the La Niña conditions cannot be identified as major warmings according to standard defining (Butler et al. 2015). The simplest way to avoid the problem is to consider the changes of the temperature and mean zonal wind at the higher altitudes and/or averaged over some altitude range, for instance, between 30 and $50 \mathrm{~km}$. However, to resolve this problem the neutral ENSO phase has been considered as the next step, which helps to make a conclusion what (El Niño or La Niña) events influence extra-tropical stratosphere more significantly.

\section{Abbreviations}

ENSO: El Niño Southern Oscillation; JRA-55: Japanese 55-year Reanalysis; MEI: Multivariate ENSO Index; MERRA: Modern-Era Retrospective Analysis for Research and Applications; MUAM: Middle and Upper Atmosphere Model; ONI: Oceanic Niño Index; SOI: Southern Oscillation Index; SPW: stationary planetary wave; SSW: sudden stratospheric warming.

\section{Authors' contributions}

AP initiated the study and prepared the manuscript. ET wrote the initial draft version of the manuscript. MM performed the preliminary MERRA data processing. OA dealt with the parameterization of the latent heat. AP performed the ensemble simulation with the MUAM. TE and IS performed the composite analysis of the results of simulation with the MUAM and MERRA data and were involved in the discussions of results obtained. All authors contributed to interpret the results, write the discussion, and revise the manuscript. All authors read and approved the final version of the manuscript. 


\section{Acknowledgements}

We appreciate the financial support (Grant Number 18-05-01050) from the Russian Foundation for Basic Research.

\section{Competing interests}

The authors declare that they have no competing interests.

\section{Availability of data and materials}

The results of ensemble simulation with the MUAM are available from the corresponding author upon request.

\section{Consent for publication}

Not applicable.

\section{Ethics approval and consent to participate}

Not applicable.

\section{Funding}

This research was supported by the Russian Foundation for Basic Research under Grant Number 18-05-01050.

\section{Publisher's Note}

Springer Nature remains neutral with regard to jurisdictional claims in published maps and institutional affiliations.

Received: 17 September 2018 Accepted: 9 January 2019

Published online: 21 January 2019

\section{References}

Brönnimann S, Schraner M, Müller B, Fischer A, Schnadt C, Brunner D, Rozanov E, Egorova T (2006) The 1986-1989 ENSO cycle in a chemical climate model. Atmos Chem Phys 6:4669-4685

Butler AH, Polvani LM (2011) El Niño, La Niña, and stratospheric sudden warmings: a reevaluation in light of the observational record. Geophys Res Lett 38:L13807. https://doi.org/10.1029/2011GL048084

Butler A, Seidel D, Hardiman S, Butchart N, Birner T, Match A (2015) Defining sudden stratospheric warmings. Bull Am Meteor Soc 96(11):1913-1928. https://doi.org/10.1175/BAMS-D-13-00173.1

Camp CD, Tung K-K (2007) Stratospheric polar warming by ENSO in winter: a statistical study. Geophys Res Lett 34:L04809. https://doi. org/10.1029/2006GL028521

Chen P, Robinson WA (1992) Propagation of planetary waves between the troposphere and stratosphere. J Atmos Sci 49:2533-2545

Coelho CAS, Goddard L (2009) El Niño-induced tropical droughts in climate change projections. J Clim 22(34):6456-6476

Ermakova TS, Statnaya IA, Fedulina IN, Suvorova EV, Pogoreltsev AI (2017) Three-dimensional semi-empirical climate model of water vapor distribution and its implementation to the radiation module of the middle and upper atmosphere model. Russ Meteorol Hydrol 42(9):594-600. https:// doi.org/10.3103/S1068373917090060

Forbes JM, Hagan ME, Zhang X, Hamilton K (1997) Upper atmospheric tidal oscillations due to latent heat release in the tropical troposphere. Ann Geophys 15:1165-1175

Free M, Seidel DJ (2009) Observed El Niño-Southern Oscillation temperature signal in the stratosphere. J Geophys Res 114:D23108. https://doi. org/10.1029/2009JD012420

Garcia-Herrera R, Calvo N, Garcia RR, Giorgetta MA (2006) Propagation of ENSO temperature signals into the middle atmosphere: a comparison of two general circulation models and ERA-40 reanalysis data. J Geophys Res 111:D06101. https://doi.org/10.1029/2005JD006061

Garfinkel Cl, Butler AH, Waugh DW, Hurwitz MM, Polvani LM (2012) Why might stratospheric sudden warmings occur with similar frequency in El Niño and La Niña winters? J Geophys Res 117:D19106. https://doi. org/10.1029/2012JD017777

Gavrilov NM, Koval AV (2013) Parameterization of mesoscale stationary orographic wave forcing for use in numerical models of atmospheric dynamics. Izv Atm Ocean Phys 49(3):244-251. https://doi.org/10.1134/ S0001433813030067
Gavrilov NM, Koval AV, Pogoreltsev Al, Savenkova EN (2015) Simulating influences of QBO phases and orographic gravity wave forcing on planetary waves in the middle atmosphere. Earth Planets Space 67:86. https://doi. org/10.1186/s40623-015-0259-2

Gershunov A, Barnett TP (1998) ENSO influence on intraseasonal extreme rainfall and temperature frequencies in the contiguous United States: observations and model results. J Clim 11:1575-1586

Giannitsis C, Lindzen RS (2009) Nonlinear saturation of vertically propagating Rossby waves. J Atmos Sci 66(4):915-935

Hagan ME, Forbes JM (2002) Migrating and nonmigrating diurnal tides in the middle and upper atmosphere excited by tropospheric latent heat release. J Geophys Res 107(D24):4754. https://doi.org/10.1029/2001 J D001236

Harnik N (2009) Observed stratospheric downward reflection and its relation to upward pulses of wave activity. J Geophys Res 114:D08120. https://doi. org/10.1029/2008JD010493

Hong S-S, Wang P-H (1980) On the thermal excitation of atmospheric tides. Bull Geophys 19:56-84

Horel JD, Wallace JM (1981) Planetary-scale atmospheric phenomena associated with the Southern Oscillation. Mon Weather Rev 109:2080-2092

Hu Y, Tung KK (2002) Interannual and decadal variations of planetary wave activity, stratospheric cooling, and northern hemisphere annular mode. J Climate 15:1659-1673

Jacqmin D, Lindzen RS (1985) The causation and sensitivity of the Northern winter planetary waves. J Atmos Sci 42:724-745

Jin D, Hameed S, Huo L (2016) Recent changes in ENSO teleconnection over the western Pacific impacts the eastern China Precipitation Dipole. J Climate. https://doi.org/10.1175/JCLI-D-16-0235.1

Kanukhina AY, Suvorova EV, Nechaeva LA, Skrygina EK, Pogoreltsev Al (2008) Climatic variability of the mean flow and stationary planetary waves in the NCEP/NCAR reanalysis data. Ann Geophys 26(5):1233-1241. https:// doi.org/10.5194/angeo-26-1233-2008

Kobayashi S, Ota Y, Harada Y, Ebita A, Moriya M, Onoda H, Onogi K, Kamahori H, Kobayashi C, Endo H, Miyaoka K, Takahashi K (2015) The JRA-55 reanalysis: general specifications and basic characteristics. J Meteor Soc Jpn 93:5-48. https://doi.org/10.2151/jmsj.2015-001

Labitzke K, Van Loon H (1989) The Southern Oscillation. Part IX: the influence of volcanic eruptions on the Southern Oscillation in the stratosphere. J Clim 2:1223-1226. https://doi.org/10.1175/1520-0442(1989)002\%3c122 3:tsopit\%3e2.0.co:2

Larkin NK, Harrison DE (2005) On the definition of El Niño and associated seasonal average U.S. weather anomalies. Geophys Res Lett 32(13):13705. https://doi.org/10.1029/2005GL022738

Limpasuvan V, Hartmann DL (2000) Wave-maintained annular modes of climate variability. J Climate 13:4414-4429

Lin B (1982) The behavior of winter stationary planetary waves forced by topography and diabatic heating. J Atmos Sci 39:1206-1226

Manzini E, Giorgetta MA, Esch M, Kornblueh L, Roeckner E (2006) The influence of sea surface temperatures on the Northern winter stratosphere: ensemble simulations with the MAECHAM5 model. J Climate 19:3863-3881

Matsuno T (1970) Vertical propagation of stationary planetary waves in the winter Northern Hemisphere. J Atmos Sci 27:871-883

Nath D, Chen Wen, Zelin Cai, Pogoreltsev A, Wei Ke (2016) Dynamics of 2013 sudden stratospheric warming event and its impact on cold weather over eurasia: role of planetary wave reflection. Sci Rep 6:24174. https:// doi.org/10.1038/srep24174

Perlwitz J, Harnik N (2003) Observational evidence of a stratospheric influence on the troposphere by planetary wave reflection. J Climate 16:3011-3026

Philander SGH (1990) El Niño, La Niña and the southern oscillation. Academic Pres, San Diego, p 289

Pogoreltsev Al, Vlasov AA, Fröhlich K, Jacobi Ch (2007) Planetary waves in coupling the lower and upper atmosphere. J Atmos Solar-Terr Phys 69:2083-2101. https://doi.org/10.1016/j.jastp.2007.05.014

Pogoreltsev Al, Savenkova EN, Pertsev NN (2014) Sudden stratospheric warmings: the role of normal atmospheric modes. Geomag Aeron 54:357-372

Pogoreltsev Al, Savenkova EN, Aniskina OG, Ermakova TS, Chen W, Wei K (2015) Interannual and intraseasonal variability of stratospheric dynamics and stratosphere-troposphere coupling during northern winter. J Atmos Solar-Terr Phys 136, Part B:187-200. https://doi.org/10.1016/j.jastp 2015.08.008 
Rao J, Ren R (2016a) Asymmetry and nonlinearity of the influence of ENSO on the northern winter stratosphere: 1. Observations. J Geophys Res Atmos 121:9000-9016. https://doi.org/10.1002/2015JD024520

Rao J, Ren R (2016b) Asymmetry and nonlinearity of the influence of ENSO on the northern winter stratosphere: 2. Model study with WACCM. J Geophys Res Atmos 121:9017-9032. https://doi.org/10.1002/2015JD024521

Reed RJ, Recker EE (1971) Structure and properties of synoptic-scale wave disturbances in the equatorial western Pacific. J Atmos Sci 28:1117-1133

Rienecker MM et al (2011) MERRA: NASA's modern-era retrospective analysis for research and applications. J Climate 24(14):3624-3648. https://doi. org/10.1175/JCLI-D-11-00015.1

Salby ML (2012) Physics of the atmosphere and climate, 2nd edn. University Press, Cambridge

Sassi F, Kinnison D, Boville BA, Garcia RR, Roble R (2004) Effect of El Niño Southern Oscillation on the dynamical, thermal, and chemical structure of the middle atmosphere. J Geophys Res 109:D17108. https://doi. org/10.1029/2003JD004434

Savenkova EN, Gavrilov NM, Pogoreltsev Al (2017) On statistical irregularity of stratospheric warming occurrence during northern winters. J Atmos Solar-Terr Phys 163:14-22. https://doi.org/10.1016/j.jastp.2017.06.007
Suvorova EV, Pogoreltsev Al (2011) Modeling of nonmigrating tides in the middle atmosphere. Geomag Aeron 51(1):105-115

Taguchi M, Hartmann DL (2006) Increased occurrence of stratospheric sudden warming during El Niño as simulated by WAACM. J Climate 19:324-332. https://doi.org/10.1175/JCLI3655.1

Van Loon H, Zerefos CS, Repapis CC (1982) The Southern Oscillation in the stratosphere. Mon Weather Rev 110(3):225-229

Wu R, Hu Z-Z, Kirtman BP (2003) Evolution of ENSO-related rainfall anomalies in East Asia and the processes. J Climate 16:3741-3757

Xie F, Li J, Tian W, Zhang J, Shu J (2014a) The impacts of two types of El Niño on global ozone variations in the last three decades. Adv Atmos Sci 31(5):1113-1126. https://doi.org/10.1007/s00376-013-3166-0

Xie F, Li J, Tian W, Zhang J, Sun C (2014b) The relative impacts of El Niño Modoki, canonical El Niño, and QBO on tropical ozone changes since the 1980s. Environ Res Lett 9(6):064020. https://doi.org/10.1088/17489326/9/6/064020

\section{Submit your manuscript to a SpringerOpen ${ }^{\circ}$ journal and benefit from:}

- Convenient online submission

- Rigorous peer review

- Open access: articles freely available online

- High visibility within the field

- Retaining the copyright to your article

Submit your next manuscript at $\boldsymbol{\nabla}$ springeropen.com 